03.1

\title{
Метод управления аэродинамическим сопротивлением цилиндра с газопроницаемыми пористыми вставками путем регулирования донного давления
}

\author{
(C) С.Г. Миронов ${ }^{1,2}$, И.Р. Валиуллин ${ }^{1}$, Т.В. Поплавская ${ }^{1,2}$ \\ ${ }^{1}$ Институт теоретической и прикладной механики им. С.А. Христиановича СО РАН, Новосибирск, Россия \\ ${ }^{2}$ Новосибирский национальный исследовательский государственный университет, Новосибирск, Россия \\ E-mail: mironov@itam.nsc.ru
}

Поступило в Редакцию 21 декабря 2020г.

В окончательной редакции 21 января 2021 г.

Принято к публикации 21 января 2021 r.

\begin{abstract}
Приведены результаты экспериментального и численного исследования сверхзвукового $\left(\mathrm{M}_{\infty}=7\right)$ обтекания полого цилиндра с газопроницаемыми пористыми вставками, расположенного вдоль потока. Показана возможность управления аэродинамическим сопротивлением модели путем перепуска части набегающего потока в донную область через газопроницаемые пористые вставки. Регулирование расхода воздуха, направляемого в донную область для управления сопротивлением, осуществлялось с помощью нагревания пористых вставок электрическим тлеющим разрядом.
\end{abstract}

Ключевые слова: аэродинамическое сопротивление, управление, пористые материалы.

DOI: 10.21883/PJTF.2021.08.50853.18680

Для сверхзвукового летательного аппарата (ЛА) донное сопротивление, возникающее вследствие разрежения в следе за ЛА, составляет значительную долю силы аэродинамического сопротивления. Подача в донную область небольшого количества газа, составляющего $\sim 1-2 \%$ от расхода набегающего потока, позволяет существенно увеличить донное давление и, следовательно, уменьшить аэродинамическое сопротивление ЛА [1]. В исследованиях [1-3] для увеличения донного давления использован выдув в донную область холодных или горячих газов различного состава из модели ЛА. Альтернативой этому является отбор воздуха из внешнего потока и подача его в донную область через щелевые вырезы в кормовых насадках [4] или с помощью газопроницаемой пористой головной части [5]. В последнем случае донное давление изменялось механическим устройством регулирования подачи [5].

В настоящей работе на основе общего принципа управления аэродинамическим сопротивлением с помощью подачи газа в донную область предложен метод регулирования отбираемого из потока воздуха без использования механических устройств. Метод основан на изменении гидравлического сопротивления пористого материала при его нагревании электрическим тлеющим разрядом. Выполнено экспериментальное и численное исследование обтекания модели цилиндра с нагреваемыми высокопористыми вставками.

Эксперименты были выполнены в сверхзвуковой аэродинамической трубе ИТПМ СО РАН Т-327 при числе Маха $\mathrm{M}_{\infty}=7$ и единичном числе Рейнольдса $\operatorname{Re}_{1}=1.5 \cdot 10^{6} \mathrm{~m}^{-1}$. Модель (рис. 1) представляла собой полый тефлоновый цилиндр длиной $42 \mathrm{~mm}$ с внешним диаметром $27 \mathrm{~mm}$ и толщиной стенки $1.5 \mathrm{~mm}$. Передний и задний торцы цилиндра были заглушены двумя газопроницаемыми пористыми вставками из ячеисто-пористого никеля толщиной $10 \mathrm{~mm}$ с диаметром пор $d=1 \mathrm{~mm}$ и величиной пористости 95\%. Пористые вставки являлись электродами тлеющего разряда, возникающего между ними внутри цилиндра при подаче напряжения. Передняя вставка являлась катодом, задняя - анодом. Цилиндр устанавливался вдоль потока на тензовесы с помощью державки из трех тонких консолей. На оси симметрии в донной области на расстоянии $4 \mathrm{~mm}$ от задней торцевой вставки была установлена медь-константановая термопара, которая измеряла температуру воздуха, прошедшего через обе пористые вставки. Показания термопары являлись индикатором эффективности нагревания воздуха при его прохождении в донную область через пористые вставки. Такая геометрия модели наиболее прямо реализует принцип отвода части набегающего потока в донную область. Модель без нагревания вставок имеет коэффициент сопротивления $C_{x 0}=1.51$ при его максимальной величине для сплошного цилиндра 1.84. В пределах разницы этих коэффициентов возможно управление аэродинамическим сопротивлением модели.

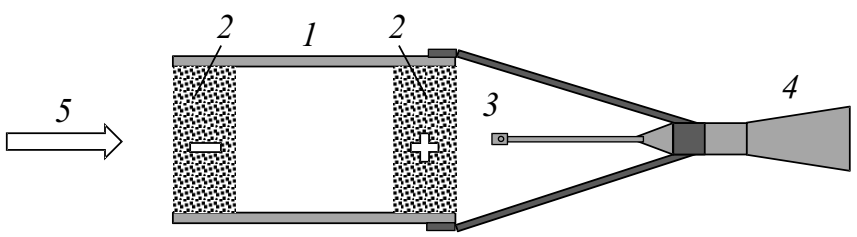

Рис. 1. Схема модели. 1 - тефлоновый цилиндр, 2 - газопроницаемые пористые вставки, 3 - термопара, 4 - тензовесы, 5 - набегающий поток. 

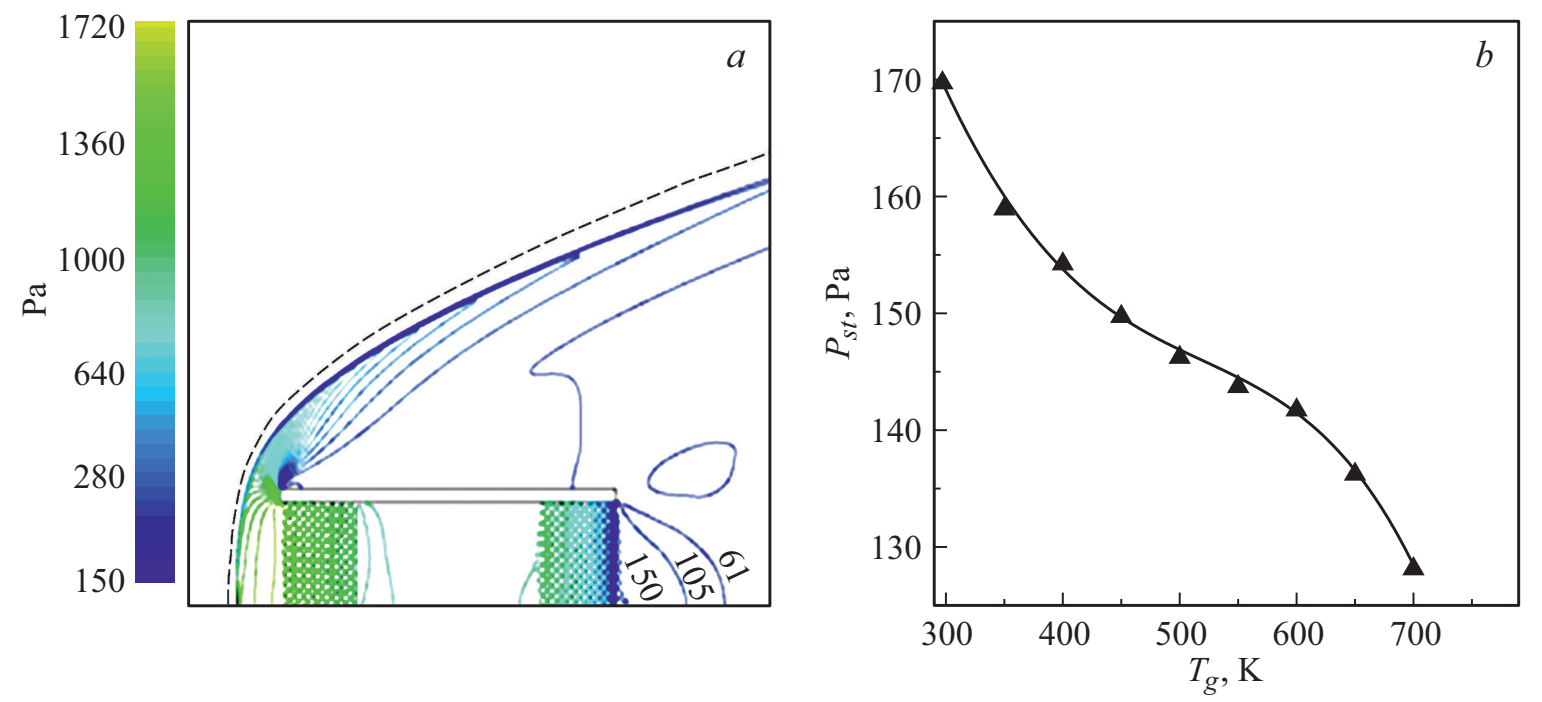

Рис. 2. $a-$ изолинии статического давления при температуре воздуха в донной области $T_{g}=297 \mathrm{~K}$, штриховая кривая положение головной ударной волны при температуре $T_{g}=700 \mathrm{~K} . b-$ зависимость статического давления на оси симметрии вблизи задней пористой вставки от температуры воздуха в донной области $T_{g}$.

В эксперименте в аэродинамической трубе производилась одновременная регистрация температуры воздуха в донной области и величины силы сопротивления модели. По данным весовых измерений строились зависимости силы аэродинамического сопротивления модели $F$ от температуры прошедшего через нее воздуха $T_{g}$. В экспериментах варьировалась мощность электрического тлеющего разряда в диапазоне от 40 до $190 \mathrm{~W}$ путем изменения величины балластного сопротивления в цепи разряда, что составляет от 11 до 53\% мощности набегающего потока. Поскольку основная энергия разряда выделяется на пористых электродах, это дает возможность нагрева пористого материала вставок.

В специальных экспериментах термопарами измерялось распределение температуры на оси торцевой вставки при ее обтекании сверхзвуковым потоком воздуха и нагревании со стороны донной области электрическим тлеющим разрядом. Измерения показали практически линейный рост температуры материала вставки по продольной координате, отсчитываемой от переднего торца. В отсутствие набегающего потока разряд проникал в пористый материал на всю длину вставки, обеспечивая ее равномерный нагрев.

Задача численного моделирования осесимметричного обтекания цилиндра с газопроницаемыми торцевыми вставками решалась с использованием пакета ANSYS Fluent в рамках двумерных уравнений Навье-Стокса, осредненных по Рейнольдсу, с использованием $k$ - $\omega$-SST-модели турбулентности, неявных схем второго порядка точности по пространству и Roe-FDS методом расщепления для аппроксимации конвективных потоков. Для моделирования торцевых газопроницаемых вставок использовалась кольцевая скелетная модель пористой среды [6,7], в плоскости осевого сечения представляющая собой набор непроницаемых квадрат- ных элементов, расположенных в шахматном порядке, расстояние между которыми в радиальном и осевом направлениях равно диаметру пор.

Проекция расчетной области на плоскость представляет собой прямоугольник, нижняя сторона которого совпадает с осью симметрии цилиндра (рис. 2, $a$ ). Внутри цилиндра и в пористых вставках расчетная область покрывалась равномерной прямоугольной расчетной сеткой, вне цилиндра расчетная сетка сгущалась вблизи переднего торца модели и к поверхностям цилиндра. На поверхности цилиндра и на каждом элементе скелета пористой вставки задавались условия прилипания и постоянства температуры. Для задания температуры на элементах скелета передней торцевой вставки, согласно данным измерений (см. выше), использовалась линейно возрастающая зависимость температуры. Минимальная температура равнялась температуре торможения $297 \mathrm{~K}$, а максимальная полагалась равной температуре воздуха $T_{g}$, измеренной в донной области. Температура на элементах скелета задней торцевой вставки полагалась равной температуре $T_{g}$ по всей длине вставки. Коэффициент аэродинамического сопротивления модели вычислялся по соотношению $C_{x}=F /\left(0.5 \rho_{\infty} u_{\infty}^{2} S_{m}\right)$, где $\rho_{\infty}$, $u_{\infty}$ - плотность и скорость набегающего потока, $S_{m}-$ площадь миделя модели, $F$ - аэродинамическая сила, определяемая в пакете ANSYS Fluent и включающая в себя силу давления и силу трения.

На рис. 2, а приведены изолинии статического давления для $T_{g}=297 \mathrm{~K}$, штриховой кривой на рисунке показано положение головной ударной волны при $T_{g}=700 \mathrm{~K}$. Расчетная зависимость статического давления $P_{s t}$ на оси симметрии модели вблизи задней торцевой вставки от температуры воздуха $T_{g}$ приведена на рис. $2, b$. Из данных рис. 2 видно, что при нагревании пористых вставок давление в донной области падает, го- 


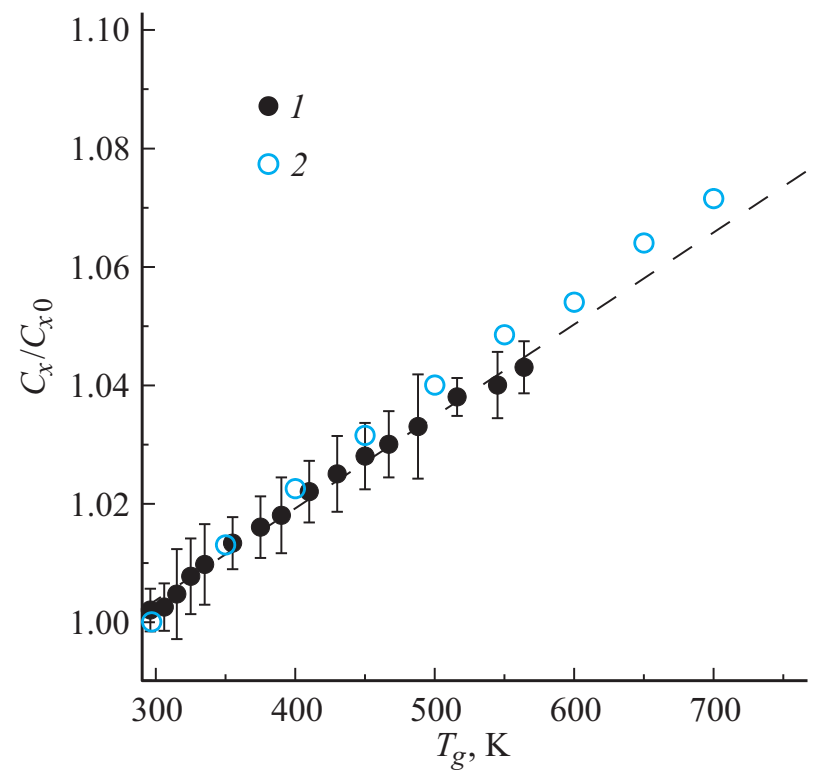

Рис. 3. Зависимость нормированного коэффициента сопротивления модели от температуры воздуха в донной области. 1 - эксперимент, 2 - расчет.

ловная ударная волна смещается вверх по потоку и угол ее наклона к направлению потока увеличивается, что связано с уменьшением расхода воздуха, перетекающего в донную область. Вследствие этого должен возрастать коэффициент аэродинамического сопротивления $C_{x}$.

Весовые измерения показали однозначную связь между коэффициентом сопротивления $C_{x}$ и температурой воздуха в донной области $T_{g}$ независимо от мощности тлеющего разряда. Это позволило обобщить экспериментальные данные в виде единой зависимости, представленной на рис. 3. Видно практически линейное возрастание нормированного коэффициента сопротивления $C_{x} / C_{x 0}$ от температуры $T_{g}$. На рис. 3 также приведены данные численного моделирования. Видно совпадение результатов эксперимента и расчета.

Таким образом, выполнено экспериментальное и численное моделирование обтекания сверхзвуковым потоком полого цилиндра с газопроницаемыми пористыми вставками, нагреваемыми электрическим тлеющим разрядом. Получены зависимости относительного увеличения аэродинамического сопротивления от температуры прошедшего через модель воздуха. Продемонстрирована возможность управления аэродинамическим сопротивлением с помощью регулирования подачи воздуха в донную область модели при нагревании электрическим тлеющим разрядом пористых вставок.

\section{Финансирование работы}

Работа выполнена при финансовой поддержке Российского фонда фундаментальных исследований (проект 19-08-00113).

\section{Конфликт интересов}

Авторы заявляют, что у них нет конфликта интересов.

\section{Список литературы}

[1] А.И. Швец, И.Т. Швец, Газодинамика ближнего следа (Наук. думка, Киев, 1976).

[2] В.К. Баев, А.Ф. Гаранин, П.К. Третьяков, Физика горения и взрыва, 11 (6), 859 (1975).

[3] А.Ф. Гаранин, А.И. Глаголев, А.И. Зубков, Л.Д. Сухановская, Изв. РАН. Механика жидкости и газа, № 2, 158 (2002). [Пер. версия: 10.1023/A:1015822703200].

[4] Г.Л. Гродзовский, Ю.А. Лашков, Г.П. Свищев, И.Н. Соколова, Учен. зап. ЦАГИ, 3 (2), 21 (1972).

[5] В.М. Фомин, В.И. Запрягаев, А.В. Локотко, В.Ф. Волков, А.Е. Луцкий, И.С. Меньшов, Ю.М. Максимов, А.И. Кирдяшкин, Прикл. механика и техн. физика, № 1, 79 (2010). [Пер. версия: 10.1007/s10808-010-0010-5].

[6] С.В. Кириловский, А.А. Маслов, С.Г. Миронов, Т.В. Поплавская, Изв. РАН. Механика жидкости и газа, № 3, 78 (2018). [Пер. версия: 10.1134/S0015462818030102].

[7] A.A. Maslov, S.G. Mironov, T.V. Poplavskaya, S.V. Kirilovskiy, J. Fluid Mech., 867, 611 (2019). https://doi.org/10.1017/jfm.2019.165 